\title{
Pediatric Cavernous Sinus Syndrome as the Initial Presentation of Intracranial Germinoma: A Case Report
}

\author{
Chuman H*, Takako S and Nao-i Nobuhisa \\ Department of Ophthalmology, University of Miyazaki, Japan
}

Submission: July 26, 2017; Published: August 04, 2017

*Corresponding author: Chuman Hideki, Department of Ophthalmology, Faculty of Medicine, University of Miyazaki, Kihara5200, Kiyotake, Miyazaki 889-1692, Japan, Tel: +81-985-85-2806; Fax: +81 985-84-0000; Email: hchuman@med.miyazaki-u.ac.jp

\begin{abstract}
8-year girl complained of diplopia and her right eye presented ptosis, supraduction, abduction deficit, slight esotropia, and corneal hypoesthesia. Visual acuity was 20/20 in both eyes. Pupillary light reflex showed full, fast constriction and afferent pupillary defect was negative. No optic disc abnormalities were observed and indicated cavernous sinus syndrome. A brain magnetic resonance imaging indicated a tumor lesion from the sellaturcica to the suprasellar region and advancing into the right cavernous sinus, compressing the optic chiasm. Tumor biopsy was performed. Histo pathological examination led to a diagnosis of intracranial germinoma. Intracranial germinoma manifest hypopituitarism and bitemporal hemianopsia but in this case, intracranial germinoma manifesting as cavernous sinus syndrome initially. Cavernous sinus syndrome represents highly in adults and pediatric cases are rare. Malignant lymphoma and Trosa-Hunt syndrome were occasionally reported as diseases causing cavernous sinus syndrome in children. But, to our knowledge, there were a few reports of intracranial germinoma. Although it is very rare, germinoma should be kept in mind as a disease which causes cavernous sinus syndrome in children.
\end{abstract}

\section{Introduction}

8-year-old girl complained of diplopia from April 2006, and started tilting her head to see things. Intermittent ptosis of the right eye appeared in May. Because right eye movement disorder was noted, she initially visited our department on October. The visual acuity was $20 / 20$ in both eyes, the light reaction was complete and rapid, and relative afferent pupillary defect (RAPD) was negative. Ptosis of the right eye was noted. The pupil diameters were 4.6 and $3.7 \mathrm{~mm}$ on the right and left sides in a bright room, respectively, and 4.6 and $5.7 \mathrm{~mm}$ in a dark room, respectively, showing laterality. The pupil diameter after a cocaine eye drop test were 4.5 and $5.7 \mathrm{~mm}$ in a bright room, respectively, being judged as positive for the test. Regarding eye movement, impairment of abduction and supraduction, mild impairment of adduction, and infraduction disorder of the right eye were observed, and corneal sensory reflex of the right eye was reduced. No abnormality was noted in the anterior segment of the eye, optic media, or fundus.Bitempolal hemianopia in visual field was observed (Figure 1). On brain magnetic resonance imaging (MRI) performed (Figure 2), a mass lesion advancing from inside the sellaturcica to the supra sellar region and right cavernous sinus was observed. Contrast enhancement of the tumor continuous from the right cavernous sinus was observed, and it advanced along the oculomotor and abducens nerves, the serum human chorionic gonad otropin- $\beta$ (hCG- $\beta$ ) level was high suggesting germ cell tumor. Regarding the systemic condition, panhypopituitarism was present, and hormone replacement therapy was initiated. Tumor biopsy was scheduled but it was postponed by her family. The visual acuity of the left eye decreased to 20/50 in February 2007, and impairment of supraduction of the right eye aggravated. On MRI performed in the same period (Figure 3), compression of the chiasma became stronger in the suprasellar region. On the right side, the tumor advanced along the orbital apex and trigeminal nerve. Tumor biopsy by craniotomy was performed on March 6, 2007. Solitary appearance of large cells containing bright and wide cytoplasm was observed on histopathological examination (Figure 4), and cells were positive for placental alkaline phosphatase (PLAP) and c-kit on immunostaining. Based on these findings, the tumor was diagnosed as intracranial germinoma. Radiotherapy and chemotherapy were immediately performed, and the tumor shrank. On follow-up in July, the visual acuity became 20/20 in both eyes, and the tumor has not recurred for 8 years. 

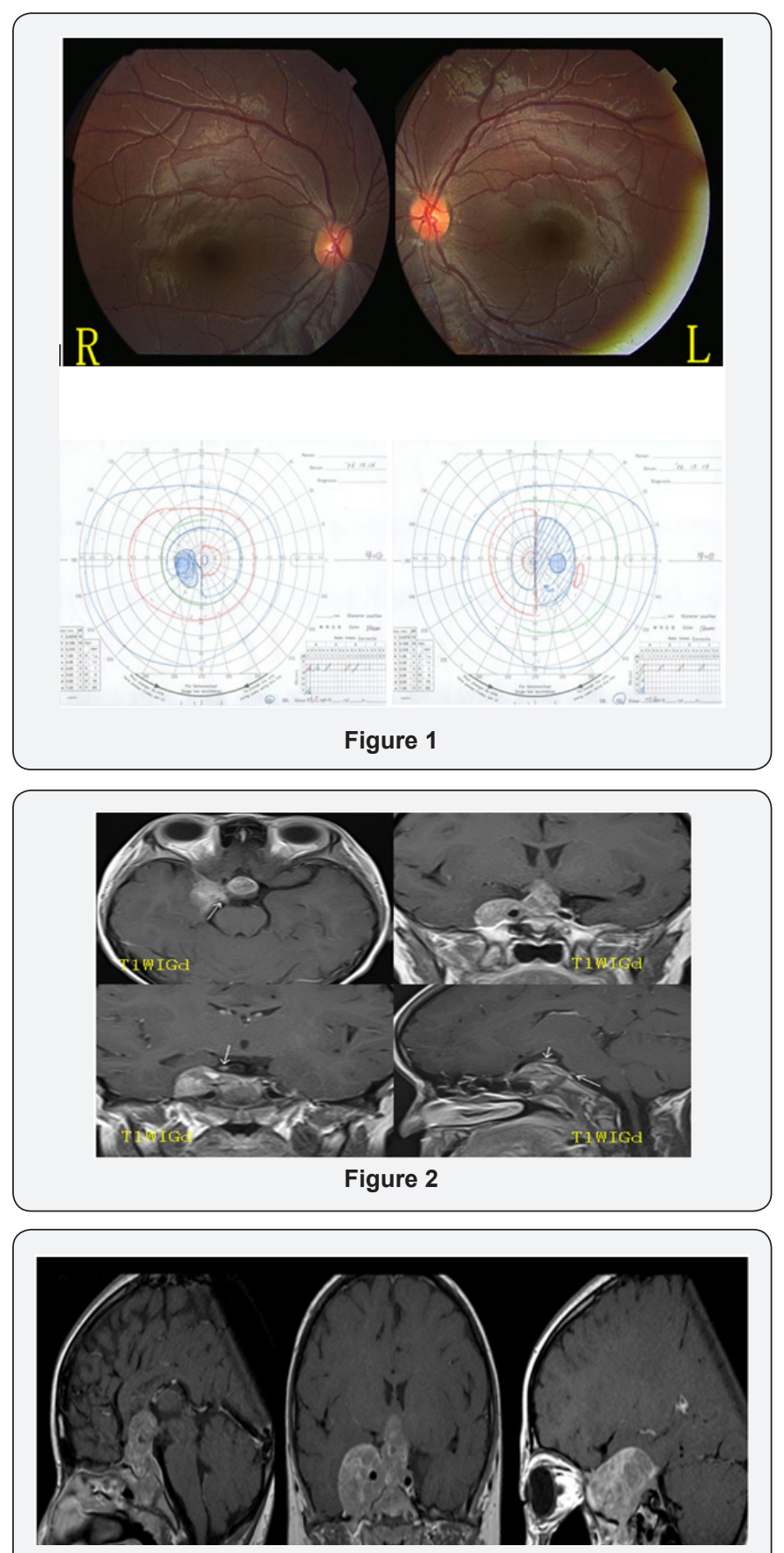

Figure 3

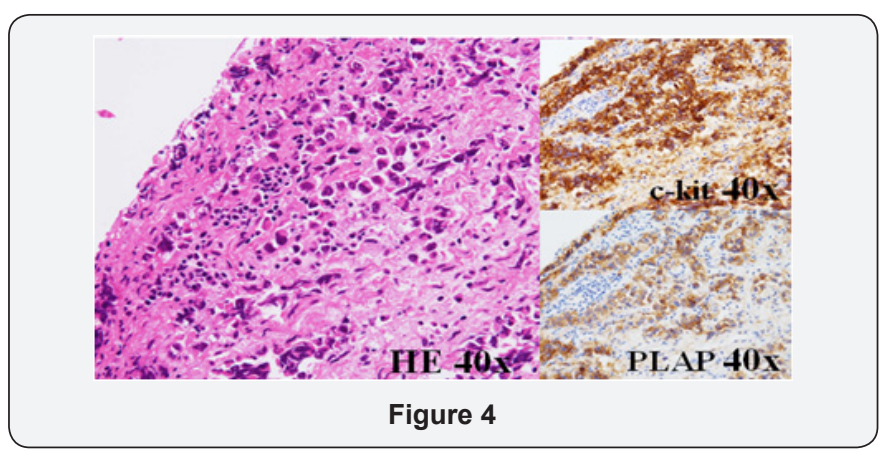

\section{Discussion}

In the present patient, diplopia and ptosis were the initial symptoms and the features of cavernous sinus syndrome complicated by Horner's syndrome were observed. These clinical findings were consistent with the mass lesion advancing from inside the sellaturcica to the suprasellar region and right cavernous sinus observed on MRI. To our knowledge, only 3 cases [1-3], of intracranial germinoma causing cavernous sinus syndrome as the initial symptoms. In these 3 cases, the tumor was heterogeneously enhanced with gadolinium on MRI and Serum or cerebrospinal fluid hCG- $\beta$ was positive.One case is children [1]. 11-year-old girl presented of left 6th cranial nerve Palsty without visual field defect. Her head MRI showed a mass mainly located in the left cavernous sinus. First biopsy want clearly histlogycal evidence of tumor cells. Intracranial germinoma was diagnosed by second biopsy five month later. Retrospective analysis of the first specimen revealed a few cells positive for c-kit immune histo chemical stain. Thus c-kit is useful for the differential diagnosis and might have resulted in early diagnosis at the first exploration. Present case test of c-kit, hCG- $\beta$ and PLAP were positive in serum or cerebro spinal fluid, so we could suspect for intracranial germinoma.

Intracranial germinoma accounts for $15 \%$ of pediatric tumor cases and it is higher in Japan than in the other western countries (3-4\%) [4]. It arises in the pineal body and suprasellar regions and induces various symptoms. Clinical manifectation are hypopituitarism and bitemporal hemianopsia. In this case, intracranial germinomam anifesting as cavernous sinus syndrome initially. Most cases occuring cavernous sinus syndrome develop in adults and pediatric cases are rare. Malignant lymphoma [5,6] and Trosa-Hunt syndrome [7-9] were occasionally reported as diseases causing cavernous sinus syndrome in children. Although it is very rare, intracranial germinoma should be kept in mind as a disease which causes cavernous sinus syndrome in children.

\section{References}

1. Ai M,Singo T, Takashi S, Shimizu T, Matsumura A (2012) Intracranial Germinoma Manifesting as Cavernous Sinus Syndrome. Neurol med Chir 52(10): 754-756.

2. Poon W, Ng HK, Wong K (1988) Primary intrseller germinoma presenting with cavernous sinus syndrome. Surg Neurol 30(5): 402405.

3. Torremocha F, Hadjadj S, Menet E (2002) Pituitary germinoma presenting as a pseudotumoral lymphocytic hypophysitis in a mam. Ann Endocrinol 63: 13-17.

4. Yajie W, Liping Z, Gao B (2010) Intracranial germinoma: clinical and MRI findings in 56 patients. Children nerv Syst 26(12): 1773-1777.

5. Arsen A, Golge A, Tulinrevide S, Demir B (2009) Cavernous Sinus Syndrome as the Initial Presentation of Childhood Non-Hodikin Lymphoma. J Pediatr Ophthalmol Strabismus 46(4): 232-234.

6. Metin D, Betul S, Ozlem ON, Nazlioğlu HO, Okan M (2010) Lymphoma of the Cavernous Sins Mimicking Tolosa-Hunt Sndrome in a Child. Pediatr Neurol 42(5): 351-354. 
7. Chia HK, Yi CH, Chun CL (2011) Unusual Clinical Course in Pediatric Tolosa-Hunt Syndrome. Pediatr Neurol 44(6): 471-474.

8. Mireiadel T, Alfons M, Elida V, Roig M (2001) Painful Ophthalmoplegia With Reversible Carotid Stenosis in a Child. Pediatr Neurol 24(4): 317319.
9. Spiteri KC, Spiteri C, Vella M (2011) An Unusual case of Pediatric Painless Ophthalmoplegia. Seminars in Opthalmology 26(2): 47-49. his work is licensed under Creative Commons Attribution 4.0 License

DOI: $10.19080 / J O J 0.2017 .04 .555626$

\section{Your next submission with Juniper Publishers} will reach you the below assets

- Quality Editorial service

- Swift Peer Review

- Reprints availability

- E-prints Service

- Manuscript Podcast for convenient understanding

- Global attainment for your research

- Manuscript accessibility in different formats ( Pdf, E-pub, Full Text, Audio)

- Unceasing customer service

Track the below URL for one-step submission https://juniperpublishers.com/online-submission.php 